folk/ed. 2021; 27(2): 419-435

DOI: $10.22559 /$ folklor.1436

\title{
Masallarda Eleştirel Düşünme: Müskürümü Sultan Masalı Örneği
}

\author{
Critical Thinking in Tales: The Case of Müskürümü Sultan
}

\section{Hülya Çevirme*}

Öz

Eleştirel düşünce, günümüzde anahtar beceri olarak kabul edilmekte, demokratik kişilik ve demokratik bir toplum geliştirebilmenin önemli ölçütü olarak geliştirilmeye çalışılmaktadır. Bu çalışma sözlü kültür ürünlerinde paradoksal olarak hem kolektif hem de eleştirel düşünme biçimlerinin var olduğunu, özellikle masal türünün günümüze taşınabilecek düzeyde eleştirel düşünme örnekleri taşıdığını ve masalın eleştirel düşünme alışkanlığının öğrenilmesi ve içselleştirilmesinde önemli bir kültürel miras kaynağı olduğunu savunmaktadır. Bu iddiaya bağlı olarak, incelemede bir Anadolu masalında eleştirel düşünme yollarını nasıl barındırdığı gösterilmeye çalışılmıştır. Öncelikle eleştirel düşünce hakkındaki literatür taranmış, daha sonra Pertev Naili Boratav'ın Masallar -1- Uçar Leyli adlı kitabından eleştirel düşünme yollarını yeterince yansıttığı belirlenen "Müskürümü Sultan” adlı masal seçilmiştir. Eleştirel düşünmenin ölçütleri ve aşamaları ise Gearld M.

Geliş tarihi (Received): 19.10.2020- Kabul tarihi (Accepted): 23.03.2021

* Dr. Öğr. Üyesi. Kocaeli Üniversitesi Eğitim Fakültesi.(Kocaeli University Faculty of Education)

hulya.cevirme@kocaeli.edu.tr. ORCID 0000-0002-1779-7306 
Nosich'den yararlanılarak oluşturulmuştur. Çalışmada Bağlam Merkezli Halkbilim Kuramı'nın İşlevsel yaklaşımına göre de doküman incelemesinden elde edilen bilgi ve veriler analiz edilmiştir. Sonuç olarak; incelenen masalda eleştirel düşünme stratejilerinin bütün aşamalarıyla kullanıldığı görülmüştür. Araştırmanın masal eleştirisi ve eleştirel düşünme becerisinin kazandırılması hakkında yapılacak çalışmalara katkısının olacağı düşünülmekte, buna bağlı olarak çok sayıda masal üzerine araştırma yapılmasını, yaygın ve örgün eğitim ortamlarında, eleştirel düşünme becerisinin geliştirilmesinin amaç edinildiği etkinliklerde, masalın da kullanılmasını önermektedir.

Anahtar sözcükler: sözlü kültür, masal, Müskürümü Sultan, eleştirel düşünme, eğitim

\begin{abstract}
Critical thinking is accepted as a key skill today and it is accepted as an important criteria to be gained for developing a democratic personality and a democratic society. This study argues that, paradoxically, there are both collective and critical ways of thinking in oral cultures; especially today, thinking about today and that the tale is an important cultural heritage in learning and internalizing critical thinking. Therefore, this study tries to show how an Anatolian tale contains critical ways of thinking. First of all, the literature on critical thinking has been scanned, then the tales in Pertev Naili Boratav's Book of Fairy Tales -1-Uçar Leyli were scanned and the tale called Müskürümü Sultan, which was determined to reflect critical ways of thinking sufficiently, was chosen. The criteria and stages of critical thinking were created by using Gearld M. Nosich. In this article, Context-Centered Folklore Theory has adopted the Functional Folklore approach and simultaneously the information and data of the article obtained from the document review are interpreted according to this theory. The studies to be made about the development of the critical thinking skills, and accordingly, it suggests that more fairy tale research should be carried out and the use of fairy tales in the activities in which it is aimed to develop critical thinking skills in educational environments.
\end{abstract}

Keywords: oral culture, fairy tale, Müskürümü Sultan, critical thinking, education

\title{
Extended summary
}

The fairy tale, which is an oral culture's literary heritage, is discussed in terms of its positive and negative effects on the ways of thinking it contains. In this discussion, folklorists advocate for the transmission of more fairy tales to younger generations, whereas some intellectuals involved in educational science, psychology, and cultural science advocate for the updating of fairy tales because they carry cultural patterns of authoritarian and individual exclusionary thinking that do not conform to modern times. It is argued that fairy tales influence the subconscious by instilling 
patriarchal stereotypes, sexism, and an ideological system with anti-democratic values, thereby limiting thinking. Nevertheless, in order to get what he wants, the hero of a fairy tale must be inquisitive and extraordinary in his way of thinking. Unlike the plot, which is simply shaped with two-dimensional fixed typing and repetitive word patterns, the tale contains a wide range of human situations and the ways in which these situations lead to different ways of thinking. In the language of the tale, connotations, references, irony, unconscious symbols, motifs, themes, and messages pave the way for critical thinking. The paradoxes of those who see the tale as a promising genre and those who see it as an obsolete genre with nothing to say for the "now" may have arisen from differences between the surface meaning of the tale and its deep meaning. Furthermore, because it is a verbal narrative, its dynamic nature, contextuality, and deep meaning make it difficult to interpret. It reinforces the stereotype that the story lacks critical thought.

Critical thinking, problem solving, decision making, asking the right questions to find the right answers, retrospective evaluation, questioning causality to better understand oneself and others, interpreting information in the face of uncertainty; it is the ability to organize one's way of thinking constructively in order to achieve results, to analyze, organize, compare, make inferences, defend, and increase thought, and solve a problem by producing a base of thought. In this case, the question is whether critical thinking can be taught. He contends that critical thinking and relevant literature can be learned. Critical thinking is a progressive thinking system with specific criteria. The following stages and criteria can be summarized: Searching for an answer to a critical question in order to solve a problem; with a well-organized plan, avoiding rigid logical thinking, focusing on the problem's unsolvable flaws or shortcomings, reconstructing the problem's rethinking, and connecting with reaching the healthy one of thought. This idea is to assess overt or implied superiority, define ideological relationships, compare previous and experimental decisions, test untested hypotheses, create new ways, analyze new viewpoints, not to conceal fears, value emotion, reconsider according to context, find consensus, and there are stages such as believing the results. These stages do not have to be in any particular order; they can be arranged in any order that best suits the problem and issue. There are ways to generate critical thinking as well as collective thinking in the depths of each tale. While there is no inherent human existence that is unaffected by culture, no culture has the power to prevent people from thinking or feeling.

This study assumes (a priori) that in oral consumer products, there are paradoxically both modes of collective and critical thought, depending on the thinking habits inherited from conventional narratives in Turkey. In contrast to the notion that logical and free thought are not established when fairy tales are examined in the proper manner, there is enough critical thinking and, in this sense, Anatolian tales have been neglected. As a result, this research attempted to demonstrate how an Anatolian story involves critical thought. First, the literature on critical thinking was scanned, followed by a scan of the tales in Pertev Naili Boratav's Book of Fairy Tales -1-Uçar Leyli that deflected randomly, and finally the tale called Müskürümü Sultan, which has been determined to adequately represent critical ways of thinking. The theoretical dimension of the study has been derived from a review of the literature on critical thinking. Context-Centered 
Folklore Theory has adopted the Functional Folklore approach in this article, and the information and data obtained from the document review are interpreted in accordance with this theory. The criteria and stages of critical thinking have been based on Gearld M. Nosich, and the technique of script analysis has been used to examine how critical thinking evolved gradually in the fairy tale.

As a result, the story under consideration demonstrated that critical thinking strategies are selected at all stages. Hence, it has been deduced that the Tale of the Müskürümü Sultan, in contrast to the acceptance of collective thought, can be read as a tale of independent, creative, democratic, and critical thinking. Pursuant thereto, the truthfulness and effort of the logic established by the little girl, who is the main character of the tale has resulted in results. In the apparent sense of the tale, the idea and action of creating a man out of wax coincides with the irrationality of attempting the impossible, but paradoxically strengthens the deep meaning. The tale of Müskürümü Sultan can also be interpreted as the life cycle blessing of the rational, free-thinking, and autonomous individual. As seen in the case study, the ways in which people in fairy tales think critically are an important source of cultural heritage for learning and internalizing the habit of critical thought in the face of today's culture's uniformity and oppression of people. Today, critical thinking is recognized as an essential ability, and it is being worked on as a criterion for creating a democratic personality and community. It is anticipated that the study will lead to future studies on the development of critical thinking skills, and as a result, further fairy tale research and the use of fairy tales in programs aimed at developing critical thinking skills in educational environments should be pursued.

\section{Giriş}

Eleştirel düşünme, bir sorunu çözmede, karar verme sürecinde doğru cevapları bulmak için doğru soruları sorma, geriye dönük değerlendirme yapma, kendini ve başkasını daha iyi anlamak için nedenselliği sorgulama, belirsizlik durumunda bilgileri yorumlama; düşünme biçimini sonuçlara ulaşmada yapıcı olarak düzenleme, olguları analiz etme, örgütleme, karşılaştırma, çıkarımlarda bulunma, savunma, düşünce kalitesini artırma, düşünce üreterek bir problemi çözme yeteneğidir. Bu durumda, eleştirel düşünme öğrenilebilir mi, sorusu akla gelmektedir. İlgili alanyazın, eleştirel düşünmenin öğrenilebileceğini savunmaktadır. (Kökdemir, 2003: 41- 48; Aslan, 2017: 19-24; Kurnaz, 2019: 5-24; İncirkuş ve Beyreli, 2019: 598). Eleştirel düşünme ölçütlerinin gerçek yaşamın sınırsız açık uçluluğu karşısında hata barındırdığı kabul edilmekle birlikte, yaşam zorluklarını aşmada büyük kolaylıklar getirdiği düşünülmektedir. Sağlıklı bir düşünme biçimi olarak eleştirel düşünmek; indirgemeci, taraflı, çarpıtılmış, önyargılı düşünce biçimlerinin karşıtıdır, nesnel bilgi ve gözlemlere değer verir. Ak1l yürütmeye, sorgulamaya, kuşkuya dayanan eleştirel düşünme becerisine sahip kişi ve toplumların özgüveni yüksektir; bu özellik yeni ve karmaşık durumlarla baş etmede geniş bir bakış açısı sağlar. Eleştirel düşünememek ise sağlıklı düşünememek ve sorun çözememektir. Eleştirel düşünememe eğlenceli, ilginç, dikkat çekici, popüler, şık, spontane, avantajl1, ben için faydalı ve modaya uygun olan düşünce biçimidir. Mantık yürütememekten, otoriteye sorgusuz inançtan, inançtan ve aşktan beslenmektir (Nosich, 2012: 159-160; Semerci, vd. 
2019). Önyargısız, özgüvenli, nesnel düşünebilen kişi ve toplumlar ise doğru düşünebildikleri için otoriter olarak yönetmekten ve yönetilmekten hoşlanmazlar (İpşiroğlu, 2015: 3-81; Aslan, 2016). Bireyler ve daha geniş çerçevede toplumlar, bir sorun karşısında çoğu zaman mantıklı düşündüklerini sanarak tepki verirler; oysaki sorunu çözmede çoğu zaman mantıklı ve yapıcı oldukları söylenemez. Bu nedenle, eleştirel düşünce günümüzde anahtar bir beceri olarak kabul edilmekte (Astleitner, 2002: 53; Boyd, 2019: 135-149), demokratik kişilik ve demokratik bir toplum geliştirebilmenin önemli ölçütü olarak sağlamlaştırılmaya çalışılmaktadır.

\section{Sözlü kültürün düşünce biçimleri}

Sözlü kültür ve ürünlerinde baskın unsurun kolektif düşünce olduğu, bireysel ve eleştirel düşünceye yeterince yer verilmediği görüşü yaygın görülmekle birlikte, kimi sözlü kültür ve ürünleri, eleştirel düşünmenin yöntemlerini örnekleriyle sunarlar. Üstelik eleştirel düşünme becerisi açısından tarihsel olarak çok eskiyle günümüz insanı arasında uçurumlar olmadığ1 da düşünülmektedir (Lévi- Strauss, 2002: 310- 312; Ong, 2010: 20- 25; Goody, 2011: 2348). Philip. K. Bock (2001: 259- 42). İnsan Davranışının Kültürel Temelleri adlı kitabında; düşünce ve davranışın kültürel etkenlere göre geliştiğini ancak evrensel insan doğasının biyolojik ve psikolojik yönlerinin kültür üzerindeki etkilerinin de gözardı edilemeyeceği ve kültürün nörobiyolojik temellerinin henüz psikolojik antropoloji açısından yanıtlanamadığını da belirtmektedir.

Günümüzde, halkın düşünce biçiminin daha kolektif olduğu (Laughey, 2010; Harari, 2015: 60-184; Enveri, 2019: 127) Asya toplumlarının kolektif veya karşılıklı bağımlı doğasına karşılık Batı toplumlarının bireyci veya bağımsız doğalarına bağlı olarak gelişen farklı düşünme alışkanlıklarının olduğu iddia edilmektedir (Nisbett, 2006: 13-173). Benzer araştırmalarda, Türkiye'de de geleneksel düşünme alışkanlığına bağlı olarak eleştirel ve özgür düşünmenin gelişmediği savunulmaktadır (Dökmen, 2016; Öztürk, 2012). Düşünce sistemleri açısından Türk halk anlatılarının yeterince incelendiği söylenemez. Umay Günay (2008, 2009: 53) eleştirel düşüncenin, istisnalar dışında, Türk halk kültürü ve ürünlerinde bulunmadığını, kolektif bilinçaltımızdaki kod ve şifrelerin eleştirel ve stratejik düşünmeyle ilgili sağlıklı yönlendirme yapamadığını belirtmekte ve "Türk milletine 21. yüzyılda verilebilecek en iyi eğitimin eleştirel ve stratejik düşünce ve uygulama kazandırmak olacağını düşünüyorum" demektedir. Nebi Özdemir (2010: 27-40) ise sözlü kültürü düşünce açısından özgünlük, farklılık kaynağı” olarak görmekte, eleştirel düşünme becerisinin Türk gülmece kültüründe var olduğunu savunmaktadır. Türkçe ders kitaplarındaki atasözlerini, eleştirel düşünceyi bulundurma durumuna göre inceleyen Batur ve Soyuçok (2019: 1119-1129) ise inceledikleri 44 atasözünün tamamında eleştirel düşünme basamaklarından en az birinin bulunduğunu belirtmişlerdir.

Oğuz (2010), Özünel (2011: 61-70), Ekici (2013: 46-47) ve Düzgün (2019) genelde halk kültürü ürünlerinin, özelde masallardaki kültürel mirasın genç kuşaklara aktarılması gerektiği görüşünde birleşmekte, Türk masallarının yeni kuşaklara yeterince aktarılmadığı 
gerçeğinden hareketle inceleme ve güncellenme çalışmalarının mutlaka uygulamalı halkbilimi yöntemleriyle yapılmasını önermektedirler.

\section{Amaç ve yöntem}

Bu çalışmanın amacı eleştirel düşünme yollarının bir Anadolu masalında nasıl yer aldığını göstermek ve bu kültürel mirası aktarmak amacıyla eleştirel düşünme içeren masalların halk eğitimi ve örgün eğitim ortamlarında kullanılmasını önermek, böylece eleştirel düşünce kültürünün oluşmasına halkbilimsel bir katkı sunmaktır. Araştırma Bağlam Merkezli Halkbilim Kuramı'nın İşlevsel yaklaşımına göre tasarlanmıştır. Ekici (2004: 99) 'ye göre; Bağlam merkezli kuramlar hem metnin şekil, yapı ve içerik özelliklerini hem de yaratım ve işlev özelliklerini bir arada değerlendirerek halk bilgisi ürünleri ve bunların sosyal bilimlerin çeşitli alanlardaki kullanım sorunlarını tartışmaya girişmeleridir. Bu bilgiye dayalı olarak da çalışma William R. Bascom (2004: 2-166)' un belirlediği folklorun kültürü gelecek kuşaklara aktarma ve eğitim işlevi çerçevesinde değerlendirilmiş, literatür taranmış daha sonra eleştirel düşünmeyi örnekleyebileceği düşünülen Pertev Naili Boratav'ın Masallar -1Uçar Leyli adlı kitabından Müskürümü Sultan (2001: 23-24) adlı masal seçilmiştir. Masala uygulanan eleştirel düşünme ölçütleri ve aşamaları ise Gearld M. Nosich (2012: 2-166)'den yararlanılarak oluşturulmuştur. Halkbilimin diğer sosyal bilimlerle aynı yöntem ve teknikleri de kullanabileceği gerçeğini dile getiren Mehmet Aça ( 2017: 200)'nın Sosyoloji, antropoloji, psikoloji, felsefe ve halk bilimi gibi disiplinler; nitel araştırma yöntemlerini kullanırlar, söyleminden de destek alınarak, doküman incelemesinden elde edilen bilgi ve veriler betimsel analiz tekniğiyle yorumlanmıştır. Döküman incelemesi tekniği olarak betimsel analiz; literatür taraması sonucunda elde edilen bilgilerin ve verilerin özetlenmesi, düzenlenmesi, yorumlanması yoluyla birtakım sonuçlara ulaşılmasıdır (Yıldırım vd., 2018: 245- 243).

\subsection{Masalda düşünme biçimleri ve işlevleri}

Toplumsal ve kişisel belleğin sanatsal görünümü olan masal sanıldığından daha çok karmaşık ve dinamik bir yapıya sahiptir. Propp (2001: 141)'un belirttiği gibi gerçeklik ise masala dolaylı olarak yansır. Bu dolaylı gerçeklikle insan; eğlenmek, ahlâki ve törel davranışlar üzerine düşünmek, toplumsal baskılardan kurtulmak ve eğitmek için masalları kurgulamıştır (Seyidoğlu, 1975: 5- 50; Bascom,1954: Çobanoğlu 2002'den aktaran Yavuz, 2002: 4; Pilanc1, 2008: 20).

Masal basitçe iki boyutlu sabit tiplemeler ve tekrarlanan söz kalıplarıyla biçimlendirdiği olay örgüsün aksine her türlü insanlık durumunu ve bu durumlarda geliştirilen düşünme biçimlerini barındırır. Masal dilindeki yan anlamlar, göndermeler, ironi, bilinç dışı semboller, motifler, tema ve iletiler eleştirel düşünmenin yollarını açar. Ancak bunu hemen görmek kolay da değildir. Masalın devingen doğası, buna bağlı olarak bağlamsal anlamı ve derin anlamının açık uçluluğu yorumunu zorlaştırır (Röhrich, 2006: 128- 144; Joosen, 2011: 152- 160). Diğer açıdan yüzey yapısında ilginç, dikkat çekici, şık, spontane, avantajlı, otoriteye sorgusuz 
inanç, inançtan ve aşktan beslenme gibi eleştirel olmayan düşüncenin standartlarını (Nosich, 2012: 159) taşıyor gibi görünmesi de masalın eleştirel düşünce barındırmadığı önyargısını beslemektedir. Propp'un masal kahramanlarının işlevlerini belirlemesi ve yüzeysel yapısını orta koyması, kuşkusuz masalın kültürel tekdüzeliğine olan inancı daha da artırmıştır. Üstelik masalın kültürle çelişen yönlerinin zaman içinde mutasyona uğratıldığı, geriye kalanlarla da kültürü kodladığı düşünülmektedir. Bir masalın yüzeysel anlamının algoritması yapıldığında Propp'un ulaştığı sonuçlara yakın sonuçlar elde edilmektedir (URL-2).

Linda Degh (1998: 91-111)'e göre de masal antik dünyanın, feodal düzenin izlerini taşır. Ancak kurgusul olarak masalın kendisi dengeli, düzenli ve mantıklı bir yapıdır, dinleyici tatmin etmek üzere yola çıkarken objektif bir yargıç gibi hareket eder. Masal kahramanı başarıya akılcı cevaplarla ulaşır. Linda Degh'in işaret ettiği mantıklılık, yargıçlık, objektiflik, akılcılık gibi özellikler eleştirel düşünmenin özellikleridir (Şahinel 2015: 123-136). Bu da masalın hem yapı hem de içeriğinin eleştirel düşünme aşamalarından bazılarına göre kurgulandığını gösterir. Bu kurgulamayı yapan kolektif akıl gizliden gizliye masalın işlevine eğitsellik katmıştır, denilebilir.

Kurtlara Koşan Kadınlar'da C. P. Estés (2016: 66-113) açıl susam açıl masal ifadesinin bir anahtar söz olarak bilgilenmeyi temsil ettiğini, ardından gelen uygun soruyu sormanın deneyimsiz ve safdil kahramana, görünenin ardındaki görünmeyeni gösterdiğini, akıllı kadının masalla zihnini açık tutarak psişik ortamını düzenlediğini belirtmektedir. Öyle anlaşılıyor ki masalın düğümü, eleştirel düşünmenin anahtarı olan açık uçlu ve özgün sorularla (Aslan, 2017: 27) çözülebilmektedir.

Masalın aileden kopuş, yolculuğa çıkma, bir yasağı çiğnemek, ergenliğin atlatılması, eş ve statü seçimi, istenen bir durum veya nesneye ulaşma veya buna engel olma, sorunu çözme gibi aşamalarında (Haase, 2016: 319- 322) kahramanın söylenenlere inanmaması sonucu otoriteyi sorgulaması, merakı ve sorularıyla sorunu çözmesi, cesur olması her sınamadan başarıyla çıkmasını sağlar. Masal kahramanları hata yapma, yeni bir şeyleri deneme, aptal görünme gibi korkuları tanımazlar. İddialarını kanıtlama çabası gösterirler. Düşünce ve davranışta çoğunluktan farklıdırlar (herkesin korktuğu deve iyi davranma vb.), farklı varlık ve insanları tanımaya açıktırlar. Ayrıca kimsenin aklına gelmeyeni deneme, blöflere çözüm üretme, bir şeyi unutma veya değiştirme, duygu ve inançlarına güven duyma, sabırlı olma gibi eleştirel düşünmede gerekli özellikleridir (Nosich, 2012: 22-39).

Peri masallarının eleştirel düşünmeyi öğretmekte olumsuz etkilere sahip oldukları (Zipes, 2018: 12-13), paradoksal olarak kadınlar açısından gerici ve engelleyici oldukları kadar ilerici ve özgürleştirici olduğu da söylenmektedir (Haase, 2004: 1-19). Peri masallarının özgürleştirici yönü, bağımsız bir varoluşla insancıl düşünmeye de olanak tanır ve ezilen küçük insanın kıvrak zekâsı ile sorununu çözmeye odaklanır (Zipes, 2018: 356- 364).

Kimi eğitim bilimci veya entelektüeller ise masalın bazı zararlı düşünce biçimlerinin kültürel kalıplarını taşıdığını, günümüz dünyasına göre güncellenmesi gerektiğini belirtmekte ve buna ek olarak masalın ataerkil stereo tip üreterek, cinsiyetçi olduğunu, demokratik olmayan değerlerle ideolojik bir sistem üreterek bilinçaltına etki ettiğini ve onu kodladığı, 
böylece düşünmeyi sınırlandırdığını savunmaktadırlar (Asutay, vd., 2018; Ulu, 2018; Cleto ve Warman., 2019; URL-4; Masykuroh, 2016: 26-34; Sezer, 2012: 13; Fisher, 1998: 20-21).

Bazı eğitimciler ise anti-kahramanların düşünce biçimlerinin çocukların özdeşiminde olumsuz etkilere neden olduğunu, özellikle soyut düşünme çağına henüz gelmemiş çocukların masallardaki şiddet ve korku ögelerinden olumsuz etkilendiklerini belirtmektedirler (Nas, 2004: 234; Güleç ve Geçgel, 2006: 48; Fırat, vd., 2013). Oysa masal kahramanı istediğini elde etmek için, düşünce biçiminde araştırıcı, sorgulayıcı ve sıra dışı olmak zorundadır. Örneğin küçük kardeş masallarında merak, itici güçtür. Merak duygusunun, öğrenme alanının genişlemesini sağlayan biyolojik temelli bir dürtü-duygu olduğu bilinmektedir (Öztürk, 2012: 10). Masalın sonunda küçük kardeşte gelişimsel olarak gerçeği değerlendirme yetisi gelişir; korkularını yener ve girişiminde başarılı olur. Küçük kardeş; aile, toplum veya kişilerin baskılarından akıllıca kurtulur, özerk benliğini inşa eder. Bu tür masallarda doğaüstü güçler ise bu denkleme hizmet eden figürler ve semboller olarak yorumlanabilir. Masal kahramanının mutlu sona ulaşması aslında toplumun sağduyusunun, kolektif aklın doğru temsilinin kahramanlaştırılması olarak da okunabilir.

Bazı masallar ise kataritiktir. Bu tür bir masalda anti-kahraman yanlış bir eylem ve düşünce içindedir; masalın ilerleyen sürecinde kötü yönlerinden, düşünme biçimini masalın aşamalarına göre dönüştürerek arınır. Binbir Gece Masalları'ındaki Şehrazat tipi kralın düşünce biçimini değiştirir. İnsan yaşam savaşı içinde, kimi zaman hırsına, kıskançlığına yenik düşer, ya da yok olma tehlikesiyle karşılaştığında kendisi de yok etmeye, kötülük yapmaya başlayabilir. Bu tip masalların çocuklardan uzak tutulması gerektiği düşüncesi, akıllı anti-kahramanla özdeşim (mimesis) kurulabilme olasılığının hesaplanmamasından kaynaklanmaktadır. Buna karşın anti-kahramanla özdeşim kuran çocuğun masalın bitiminde rahatladığı, içindeki şiddeti tanıdığı ve iç dünyasını yeniden şekillendirdiği, yıkıcı duygu ve düşüncelerden arındığı (katarsis) da düşünülmektedir (Büyü 2015: 237- 253).

Masallar akıllı tipi destekler. Eleştirel düşünme akıl yürütmeyle ilgilidir ve üstelik bu akıl yürütmede kişinin ve toplumun güce ve geleneksel olana, tek tipleştirici olana karşı düşünebilmesinin olanaklarını sunar (URL-1; Freire, 2006: 70- 194). Bazı masallarda akıllı tipe karş1 aptal tipin mücadelesi görülür. Sonuçta daha zeki olan tip istediğini elde eder (Karadağ, 2004: 194; Şimşek, 2017). Masalda iyi veya kötü kahraman eleştirel düşünebilir ancak iyi olan kahraman daha eleştirel düşünebildiği için rakibini yener. Keloğlan masalları bu tip masallardandır. Böyle masallar Jung'a göre yorumlanırsa, kötü veya anti-kahraman iyi kahramanın arketipsel gölgesi olabilir. Gölgenin kolektif yönü cadı, şeytan, hilebaz gibi kötü kahramanlarla kişileştirilebilir (Fordham, 2011: 64-65). Örneğin Köse bu bağlamda gölgenin Türk masallarındaki tipi olarak yorumlanabilir. Diğer açıdan masal da bir edebiyat ürünüdür. Edebiyat ürünleri toplumsal veya kişisel bilinç ve bilinçaltının ifadesi olarak yasak, yanlış, ahlak dışı, bencil, uyumsuz duygu ve düşünceleri barındırabilmektedir; kimi edebiyat ürünleri ise ahlak kurallarını ironik olarak ihlal eder (Bataille, 2004: 24-52). Edebiyat eleştirmeni Rita Felski'nin söylemiyle edebiyat okuru bir mikrokosmostur ve edebiyat metni etik muhakemeyi geliştirme, eleştirel mesafe, kişisel ve kamusal bilinci genişletme gibi etkileriyle bilişsel gücün kaynağı olarak baş tacı edilmelidir (2010: 29-131). 
Masalın eğitimsel değerini siyah-beyaz ahlakla değerlendirmeden daha çok masalın adaptasyonunu ve evrimini keşfetmek, mesajının ve karmaşık sanatsal doğasını eleştirel yaklaşımlarla okumak, masalın dinamik yapısını işlevini ortaya çıkarmak (URL-3) için ise daha çok araştırmaya ihtiyaç duyulduğu açıktır.

\section{2. Müskürümü Sultan Masalı’nın eleştirel düşünme aşamalarına göre incelenmesi}

Gearld M. Nosich'e göre eleştirel düşünme; mantık çerçevesinde, olay ve olguların derinliğine bakmamızı sağlayan belli ölçütleri olan aşamalı bir düşünme sistemidir. Eleştirel düşünme bir sorunu çözmek için sorulan eleştirel soruya cevap aramak; iyi düzenlenmiş bir planla, katı mantıkçılığa mesafeli durarak, problemin çözülemeyen kusur veya eksikliklerine odaklanmak, sorunun üstüne yeniden düşünmeyi yapılandırmak ve düşüncenin sağlıklı olanına ulaşmak demektir. Bu düşünme biçiminde açık veya örtük egemenliği belirleme, ideolojik ilişkileri saptama, önceki kararları ve deneyimleri yenileriyle karşılaştırma, sınanmamış kabulleri test etme, yeni yollar geliştirme, yeni bakış açılarını değerlendirme, korkuların üstünü örtmeme, duyguya değer verme, bağlama göre yeniden düşünme, fikir birliğine ulaşma ve sonuçlara inanma gibi aşamalar bulunur. Bu aşamalar sıralı olmak zorunda değildir; sorun ve soruya göre yapılandırılabilir. Bu ölçütlerin aşamaları ise şunlardır:

Açıklık; düşüncenin yanlış anlaşılma ihtimali taşımaması, belirsiz ve karışı olmaması, Doğruluk; akla yatkın biçimde ve anlaşılır şekilde ifade edilmesi, en azından ne olmadığının belirgin olmas1,

Önem ve alaka; düşüncenin sorunu doğrudan işaret etmesi, dolaylı bir alakanın olmaması,

Yeterlik; sorunun çözülmesinde düşüncenin, ihtiyacı karşılayacak düzey ve kapsamda yeterli olmas1,

Derinlik ve genişlik; sorunla ilgili bütün etkenler ve etkilerin dikkate alınması; hemen göze çarpmayana, ince ayrımlara ve nedenlerin kaynağına inebilmesi,

Kesinlik; problemin çözümünde yeteri kadar spesifik düşünebilme. Bir düşünme pratiğinin bu aşama ve ölçütleri içermesi, büyük oranda eleştirel düşünmenin gerçekleştiğini göstermektedir (Nosich, 2012: 1-222).

Nosich'nin eleştirel düşünmenin aşama ve ölçütlerine göre Müskürümü Sultan masalı analiz edildiğinde şu sonuçlara ulaşılmıştır:

1. Eleştirel soruyu sormak/belirsizliği kabul etmek, açık ve örtük olanları saptama, açıklık, kabulleri analiz etme, mantığın kontrol edilmesi, ortaya konan belgelerin bilgi açısından kontrolü: Müskürümü Sultan masalında, evlenme çağları geçmek üzere olan üç kız kardeş bir gün lalalarına (öğretmen) "Padişah babam bizi ne zaman evlendirecek" sorusunu sorarlar. Bu amaçla babalarına içi geçmiş, geçmekte olan ve tam kıvamında olan üç karpuz gönderirler. Masalın problemi padişah, kızlarının evlenme yaşının gelip geçtiğini unutmuştur. "Bunların ikisi yenmeyecek halde neden önüme getirdin?" diye sorar ama bilgi kaynă̆ olan lala sayesinde problemi anlar. Hem vezir “... Bunları ne zaman evlendireceksin” sorusuna karşılık olarak Padişahın “...̇̇i hatırlattın kendilerine sor 
bakalım, kimleri istiyorlar" diyaloğu ise sorunun ve cevabın eleştirel düşüncenin $a c ̧ ı k l ı k$ ve kabulleri analiz etmesi aşamasına denk düşmektedir. Bu aşamada üç kız kardeşin babalarına gönderdiği üç farklı olgunluk düzeyindeki karpuz, masalda eleştirel düşünme sorusunun temsili olarak yorumlanabilir. Padişahın karpuz motifi örtük olarak hem evlenme isteğini hem de ortaya konan belgeleri temsil etmektedir. Karpuzların padişah tarafından incelenmesi ise mantığın kontrol edilmesi olarak değerlendirilebilir. Edebiyat metinleri açık ve örtük anlamlarla kurgulanır. Bu masaldaki karpuz motifi barındırmakta olduğu hem örtük hem de açık anlamlarıyla halkın söylem gücünü yansıtmaktadır.

2. Çözümleme/Eleştirel düşüncenin ikinci aşaması sorunun cevabını eleştirel yolla cevaplamaktır: Bu aşamada problemin çözümü için yeterli bilgiye sahip olunup olunmadığını anlamak, varsa eksikliğin nasıl giderilebileceğine ilişkin çıkarımlar yapabilmek, karşıdaki insanın davranışının ardındaki nedeni sorgulamak, mantıklı düşünmek, alakalık/ doğruluk/ tutarlılıkla sorgulamaktır. Vezirin ...Bunları ne zaman evlendireceksin? sorusuna karşılık Padişahın ...İyi hatırlattın kendilerine sor bakalım, kimleri istiyorlar? sorusu, vezirin sorusuna karşı alakalı, tutarlı ve doğru, mantıklı bir cevaptır. Ancak padişah kızlarının evlilik yaşının gelip geçmekte olduğunun bilgisine ait soruyu, kızlarının lalasına sorduğu soruyla yanıtlar. Bu durumda padişah baba ile kızlar arasındaki iletişimin önce kopuk olduğu sonra bir soru ile yeniden kurulduğu anlamına gelir. Padişah karpuz sembolünü doğru sorularla anlamlandırmıştır. Lalayı dinlemiş olması, eleştirel düşünmede önemli bir aşama olan karşıdaki insanın davranışının ardındaki nedeni sorgulamak olarak ele alınabilir.

3. Çözümlemeye karşı çözümleme, derinlik, tutarlı ideoloji eleştiri, açık ve örtük egemenlik ilişkilerini saptamak: Eleştirel düşünmenin bu aşaması ve ölçütlerinde, problemin çözümünde olumlu sonuca ulaşmak için durumu çözümlemektir. Padişahın kızlarının Padişah babam bizi ne zaman evlendirecek? sorununun çözümlenmesi, Vezirin ...Bunları ne zaman evlendireceksin? sorusunu sormasıyla başlar; karşı çözümleme olarak padişahın ...Iyi hatırlattın, kendilerine sor bakalım, kimleri istiyorlar? sorusu, kızların sorununu boyutlandırır, soruna derinlik kazandırır. Masal bu aşamada da temel sorunun diğer bir yönünü sorgulamış olur.

Kızlardan ilki veziri, ikincisi sadrazamı eş olarak seçmek istediklerini babalarına bildirirler. En küçük kız; hiçbir şey istemem, padişah babamla konuşacağım der, ardından babasıyla görüşür, ondan odun, kazan, bal mumu ve deniz kıyısında bir ev ister. Küçük kız kardeşlerine göre ideolojik davranır çünkü farklı bir düşünceye sahiptir; bu nedenle otoritenin yardımcısı olan sadrazam veya vezir gibi kişilerle evlenmeyi seçmez. Babasıyla aracı kişi yoluyla değil, doğrudan görüşmeyi talep eder. Kahramanın bu davranışı, aslında açık ve örtük olarak babanın, yani iktidarın gücünü, padişahla diğeri arasındaki egemenlik ilişkisini baba ve kız arasındaki egemenlik ilişkisine çevirerek isteğini çözmeyi seçmesi, eleştirel düşünmenin masaldaki görüntüsüdür. Üstelik babasından istediği araçlar odun, kazan, bal mumu yüzeysel olarak mantıksız, alâkasız görünse de derin ve tutarlı bir ideoloji, yani düşünme biçimi olarak yorumlanabilir. Babanın kızı ile görüşmesi ve isteğini kabul etmesi ise yine masaldaki kişilerden babanın da kızı gibi eleştirel düşünebildiği anlamında okunabilir. 
Kızın ve babanın hiyerarşik ve otoriter davranmaması, masalın yüzeyinde padişahın kızının mantıklı görünmeyen isteklerine olumlu yanıt vermesi halkın demokratik eğilimlere verdiği değerin ve anlayışın göstergesi olarak yorumlanabilir. Kızın kız kardeşleri gibi, sarayda yaşayabilen vezir veya sadrazam gibi kişilerle evlenmeyi seçmemesi ve deniz kıyısında bir ev istemesi, yine iktidarın ve gücün dışına çıkma, evlilikte özerk birey olma ve özerk bir alan oluşturma biçiminde dışa vuran tutarlı ideolojisini yansıtmaktadır.

4. Eleştirel düşünce; sunulan bilginin değerlendirilmesinde farklı seçenekleri tartmak, değerlendirme sürecinde; akılcı kıstaslar kullanmaktır. Değerlendirme kriterleri konusunda fikir birliği yaratılmadan ortak bir karar almak mümkün olamaz. Sonuçlara inanmak, uygun şekilde davranış, yeterli, iyi düzenlenmiş bir plan gerektirir: Bu aşamada padişah, kızının isteklerini yerine getirir; kız, babasının verdiği deniz kıyısındaki evde, bal mumundan bir erkek yaratmak için kırk gün çalışır. Güzel bir erkek kalıbının içine bal mumunu dökerek yarattığı erkek heykelinin karşısında namaz kılar, dua eder. Kızın duası üzerine mumdan adam heykeli dirilir. Kırk birinci gün babasını çağırır. Babacığım şimdi bunun ismini sen koyacaksın ve bizi hemen burada evlendireceksin! der. Padişah baba, klş ve yaz solmadan yaşayabilen bir çiçeği bahçede görür ve damat adayının ismini Müskürümü koyar. Masalda kahraman küçük kız olmadık bir şey istemekle eleştirel düşüncede bir şeye inanmakla ona uygun bir şekilde davranışın sürdürülmesi örneği olarak okunabilir. Babanın, Müskürümü çiçeğini isim olarak seçmesi eleştirel düşünmede sonuçlara inanmanın masaldaki metaforu olarak okunabilir. Burada küçük kızın düşüncesi, iradesi, inancı ve çabası, yeterliliği iyi tasarlanmış plan sayesinde gerçekleşir. Küçük kızın başarısı diğer kız kardeşlerin (evlenme) alışkanlığının dışında bir davranıştır. Babanın bu plana uyması ise eleştirel düşünmede tarafların düşünce birliğine varması olarak değerlendirilebilir.

5. Eleştirel düşünme duyguya değer verir, katı mantıkçılığa mesafelidir ve güvenir, duygunun desteğini alan eleştirel düşünce yardımcı duygulardan beslenir: Bu masalda babanın sevgi duygusu, kızlarının duygularını anlaması, doğru yorumlaması ve küçük kızının pek de mantıklı görünmeyen eş seçme yolunu çocuğunun otonomi ihtiyacı olarak anlamasından geçmektedir. Kış ve yaz solmadan yaşayabilen bir çiçeğin damadın adını belirlemesi, babanın kızının eş ve evlilik sürecine, yani problemin çözümünün sürekliliğinde duygu ve mantığın birleşmesi olarak yorumlanabilir. Baba, kızının karar ve davranışlarının sonuçlarına destek vererek ona güvendiğini göstermektedir. Oysa ölçüsüz sevgi, bazen aşırı koruma ve kısıtlama ailede eleştirel düşünmenin gelişmesini engeller. Katı mantıkçılığa mesafe burada padişah babaya sevginin ve baba olmanın olumlu duygularını modellemektedir. Küçük kızının seçiminde ona yol açıcı olmuştur.

6. Eleştirel düşünce problemin çözülemeyen kusur veya eksikliklerine odaklanır bu durumda bakış açısını genişletilir ve bir olguyla ilgili seçenek, görüşler bulunur: Masalın devamında küçük kızın eş bulması şablonu, yeni duruma göre bir kez daha değerlendirilir. Bir Kral kızı, bu mumdan yapılan olağanüstü insanı, Müskürümü Sultan'1 görmek isteğiyle, muhteşem güzellikte bir gemiye atlar ve çiftin kapısına dayanır. Geminin büyüsüne kapılan Müskürümü Sultan gemiye biner; ama Kral kızı tarafından kaçırılır. Kızın erkeğini bal mumundan yapması, babanın damat adayına kış ve yaz solmadan yaşayabilen bir çiçeğin 
ismini seçmesi ve Kral kızının muhteşem güzellikteki gemisiyle sınanması, eleştirel düşüncede en son kararın gücü, etkililiği, yeterliliği, bakış açısı yeniden gözden geçirilerek değerlendirilmesi olarak okunabilir çünkü bal mumundan yapılmış eş, istenildiği gibi şekillendirilmiş tek taraflı olarak inşa edilmiştir.

Evlilikte gönüllülük, devamlılık ve sevgi iradesinin sorgulandığı bu bölüm, evliliğin basmakalıp ifadelerine karşı bir sorgulamadır, çünkü geminin güzelliğine aldanma ve kaçırılmanın derin anlamında, evlilikte sevginin sürekliliği veya sadakatsizliğin yarattığı kusuru onarma çabası olarak da yorumlanabilir.

7. Eleştirel düşünce benmerkezci değildir, adil olmayı ve duygudaşlık (empati) kurmayı gerektirir: Küçük kız ilk önce benmerkezci davranmaya kalkışır ama sonra kararını değiştirir, sadece kendi ihtiyaç ve isteklerine bağlanmayıp eşinin de isteklerine adil ve empatik yaklaşır. Kızın, eşinin muhteşem gemiyi gezme isteğini önce reddetmesi, sonra ...Peki, yarım saat kadar gidebilirsin! demesi eleştirel düşünmede empatiyi temsil edebilir.

8. Eleştirel düşünce varılan sonucun güvenilir olmasını da sınar: Kaçırılma olayında Müskürümlü Sultan'ın kusuru yokmuş gibi görülebilir ancak derin yapıda "Ne olur bu gemiyi ben de gezeyim" demesi, evlilikteki sevgisinin ve sadakatinin sorgulanması olarak yorumlanabilir.

Eleştirel düşünmede karşı düşünceyi duymamak, adil olmamak ve empati kuramamak düşünce ve inancın geçerliliğini kuşkuya düşürür. Masalda bu bölüm, benmerkezci düşünceyi aşmanın örneğini sunmaktadır.

Masalda küçük kız, kaçırılan eşini bulmak için babasından altın çarık, kendi sarıp kendi dokuyacak altından bir gergef ve bir kuluçka ister. -Yeni durum karşısında baba yine kızına destek olur. Küçük kız, Kral kızının kapısına dayanır, altın gergefi gören (mal mülk) Kral kızı, Müskürümü Sultan’ın bir gece şehzadeyle yatması karşılığında, gergefe sahip olur. Masalın bu bölümü kızın sevgi, sadakat gibi evliliğin temel bileşenlerini önceki karar ve deneyimiyle, yeniden test etmesidir. Küçük kızın, altından geriye kalan iki eşyasını da Kral kızına vererek üç kez Müskürümü Sultan'la yatmak istemesi, eleştirel düşünmede içinde bulunduğu durumu, yani eşinin kendisini sevip sevmediğini ya da ihanet edip etmediğini ya da evliliğinin sürekliliğini denemesi anlamına gelir. Bu durum eleştirel düşüncede, problemin çözümünde karşılaşılan korku ve eksikliklerle yüzleşme aşamasıdır. Bu yüzleşmede daha önceki birikimin sorgulanması, problemin mutlak çözümünde yeni bakış açılarıyla, düşünce alışkanlıklarından kurtulma, derinlikli düşünme ve problemi yeniden yapılandırma ve sınanmış kabulleri test etmek için yeni yollar arama, aşamasıdır. Masalda bu aşama, Kıral kızının Müskürümü Sultan'1 iksirle uyutması sonucu gerçekleşir. Bu iksir aslında sevginin ve sadakatin sorgulanması anlamında eleştirel düşüncede problemi çözmek için unutmak, yeniden ögrenmek ve değiştirmek aşamalarının temsilidir.

9. Eleştirel düşünme disiplinli bir çabadır ve düşünce hızını yavaşlatabilir: Eleştirel düşünmenin bu aşamasında Müskürümü Sultan eşini uyandırmak ve gerçeği anlatmak için ancak üçüncü denemede başarılı olur. Uykudan uyanmama ve bu engelini üçüncü kezde, tekrar edilerek aşılması, yeniden mantık kurmanın iz düşümü olarak problemin yeniden 
resmedilmesi olarak yorumlanabilir. Müskürümü Sultan eşine kavuşmak için her denemede sonucunda başarısızlığın acısını çeker ve eşine ulaşma süreci uzar. Bu denemeler, problemin anlaşılması için yeniden disiplinli bir çaba harcamak demektir; bu ise doğal olarak karara varma sürecini yavaşlatır.

10. Eleştirel düşünme bağlamı yeniden düşünmeyi gerektirir: Masalın sonuna doğru küçük kız "Balmumundan yaptıcă̆ım kırk gün namaz kıldıcă̆ım, uyan, Müskürümü Şehzade uyan!" diye ağlar, ancak eşi iksirin etkisiyle ancak sabah uyanır. Seyis gece olanları Müskürümü Sultan'a anlatır. Metafor olarak uyku ve uyanmak bağlamı, yeniden düşünmeye denk düşmektedir.

11. Eleştirel olmayan düşünce ölçütlerinden derin bir inanç, aşka benzer duygu durumlarıdır. Eleştirel düşünmenin son aşamasında ise problemin, düşüncenin sağlıklı ve gerçek olanına ulaşılır: Masalda küçük kız; ilişkisine inancını, aşkını, duygu durumunu, yeniden yeni bir bağlamda dener, başka bir kadınla birlikte olan, eşini aldatan veya terk eden şehzade de ilişkisini sorgulamış, eşini değiştirmeyi düşünmüş ve sonuçta eşine geri dönmüştür. Uyku hali iki kahramanın da evliliklerindeki saklı sorunun örtülmesi, şehzadenin uykulu halden uyanık hale geçmesi ve tekrar küçük kızla sarayına geri dönmesi, sorunun çözümü olarak yorumlanabilir. Padişahın küçük kızının eş edinme, evlenme mutluluğu sağlanmış, problemi çözülmüştür. Ancak masalın son cümlesi $O$ günden sonra da Müskürümlü Şehzade bir daha sokağa çıkmamış! cümlesi, insan ilişkilerinin, evlilikte güvenli limanların, her an bir firtınayla sarsılabileceği gerçeği, eleştirel düşünmenin doğasında var olan sürekli sorgulama veya edebiyat ürünlerinin açık uçluluğunun sembolik ifadesi olarak da yorumlanabilir.

\section{Sonuç}

Bireysel ve kültürel benliğin ve belleğin diyalektiği olarak masal hem kolektif hem de eleştirel düşüncenin görünümlerini sunmaktadır. Bu nedenle masalı sadece kolektif bilincin ve düşüncenin arkaik bir kalıntısı olarak görmek sı̆̆ bir bakıştır. Bir edebiyat ürünü olarak masal da edebiyatın ironik doğasını fazlasıyla taşımaktadır. Masalın, yazarı olan herhangi bir edebiyat metninden farkı, olsa olsa anonimliği ve çok daha yüzeysel görünmesidir. Kültürden bağımsız evrensel bir insan doğası olmasa da hiçbir kültür düşünmeyi veya duyguyu yasaklayabilecek güce sahip değildir. Kültür standart düşünme biçimlerini barındırır ancak var olan kalıbın dışına da taşar. Masal, kişi ile toplum arasında dengeyi sağlar. Asıl kaynağında yatan özgür ve eleştirel düşünmenin hem bireysel hem de kolektif görünümlerini birlikte barındırır. Müskürümü Sultan masalı bu tür masallara uygun bir örnektir.

Müskürümü Sultan ortak davranış kabullerinin aksine bağımsız ve aykırı davranışın bireyi başarıya götürüşünün, eleştirel düşünebilmenin masalı olarak okunabilir. Küçük kızın kurduğu mantığın doğruluğu ve çabası sonuç vermiştir, bal mumundan erkek yaratmak düşüncesi ve eylemi masalın yüzey anlamında imkânsız olanı denemenin mantıksızlığına denk düşmekte, paradoksal olarak ise derin anlamı güçlendirmektedir. Derin yapıda yaşam döngüsü içinde yaratıcı, demokratik, özgür düşünceli ve özerk benlikli bireyin kutsanması olarak yorumlanabilir. Sonuç olarak, masalda, Müskürümü Sultan masalı örneğinde de 
görüldüğü gibi, halkın eleştirel düşünme biçimi görülebilmektedir. Masal, eleştirel düşünme alışkanlığını öğrenilmesi ve içselleştirilmesi için önemli bir kaynaktır, diyebilmek için, kültürel miras olarak masalın günümüze taşınması, kadim anlatı olarak yeniden işlev kazanması için ise daha çok masal üzerinde çalışılmasını gerektiriyor.

Müskürümü Sultan masalı eleştirel düşüncenin bütün aşamalarını taşıyan tipik bir örnektir. Ancak bu kadim anlatı türünün tarihsel işlevini sürdürmesi, günümüze taşınması için daha çok örnek üzerinde çalışmayı gerektirmektedir. Yeterli araştırmalardan sonra masal, eleştirel düşünme alışkanlığını öğrenilmesi ve içselleştirilmesi için önemli bir kaynak olarak daha çok değer kazanacaktır.

\section{Kaynakça}

Aça, M. (2019). Halk Bilimi veri toplama ve inceleme teknikleri. M. Aça (ed.) Halk Bilimi El kitabı. Ankara: Nobel Akademik.

Aslan, C. (2016). Özerk benlikli birey yetiştirme sürecinde çağdaş dil ve edebiyat öğretimi ortamlarının (Türkçe/Türk Dili ve Edebiyatı) önemi. İlköğretim Online, 15(3), 724- 728.

Aslan, C. (2017). Örnek eğitim durumlarılla Türkçe-Türk Dili ve Edebiyatı öğretimi. Ankara: Anı.

Asutay, H. ve Agvan, Ö. (2018). Bir anti-masal örneği olarak cam ayakkabıları reddeden vejetaryen Külkedisi. Humanitas-Uluslararası Sosyal Bilimler Dergisi, 6, 225-238.

Astleitner, H. (2002). Teaching critical thinking. Online Journal of Instructional Psychology, 29(2), 53-76.

Bataille, G. (2004). Edebiyat ve kötülük.( A. Sönmezay, Çev.) İstanbul: Ayrıntı.

Batur, Z. ve Soyuçok, M. (2019). Atasözlerinde eleştirel düşünme unsurları: Türkçe ders kitapları. Folklor/Edebiyat, 25(100), 1119-1128.

Bock, K. P. (2001). Insan davranışının kültürel temelleri: Psikolojik antropoloji. (S.N. Altuntek, Çev.) Ankara: İmge.

Boyd, N. L. (2019). Using argumentation to develop critical thinking about social issues in the classroom: A dialogic model of critical thinking education. Handbook of Research on Critical Thinking and Teacher Education Pedagogy. IGI Global, 135-149.

Büyü, G. T. (2015). Masalların katartik etkisi: Kötülüklerden arınma. Ankara: Doğu Batı Düşünce Dergisi, 71, 237- 253.

Cleto, S. ve Warman. B. (2019). Teaching with Stories: Empathy, relatability, and the fairy tale. Marvels \& Tales, 33 (1), 02-115.

Güleç, Ç. H. ve Geçgel, H. (2006). Çocuk edebiyatı. Ankara: Kök.

Çobanoğlu, Ö. (2002). Halkbilimi kuramları ve araştırma yöntemleri tarihine giriş. Ankara: Akçağ.

Degh, L. (1998). Halk anlatısı. (Z. Karagülle, Çev.) Millî Folklor, 39, 91- 111.

Dökmen, Ü. (2016). İnsanın korunaklarl- 1: Deriden kültüre. İstanbul: Remzi. 
Düzgün, D. (2019). Halk kültürü değişmeleri ve bir alan araştırması. Millî Folklor, 31. (124), s. 72.

Ekici, M. (2004). Halk bilgisi (Folklor) derleme ve inceleme yöntemleri. Ankara: Geleneksel.

Ekici, M. (2013). 100. yılında Türk halk bilimi çalışmaları ve Türkiye kültür politikalarına eleştirel bir bakış. Millî Folklor, 99, 50.

Estés, C. P. (2016). Kurtlara koşan kadınlar. (H. Atalay, Çev.) İstanbul: Ayrıntı.

Enveri, E. (2019). Kolektif akıl ve Folklor: Sözlü geleneğin anonimliği üzerine. Kültür Araştırmalarl Dergisi, 1(2), s.127.

Felski, R. (2010). Edebiyat ne işe yarar. (E. Ayhan Çev.) İstanbul: Metis Eleştiri.

Fırat, H. vd. (2013). Okul öncesi dönem çocuklarına yönelik hazırlanan masal ve öykü kitaplarının korku ve şiddet öğeleri açısından incelenmesi. The Journal of Academic Social Science Studies, 6 (5), 217-241.

Freire, P. (2006). Ezilenlerin pedagojisi. (D. Hattatoğlu, E. Özbek, Çev.) İstanbul: Ayrıntı.

Fisher, R. (1998). Stories for thinking: Developing critical literacy through the use of narrative. Analytic Teaching, 18, 1 .

Fordham, F. (2011). Jung psikolojisinin ana hatlart. (A. Yalçıner, Çev.) İstanbul: Say.

Günay, U. (2008). Sosyal bilimler- eleştirel ve stratejik düşünce ilişkisi. Millî Folklor, 80, 21-25.

Günay, U. ( 2009). Türk kültürüne eleştiri. Ankara: Akça.

Goody, J. (2011). Yaban aklın evcilleştirilmesi. (K. Değirmenci, Çev.) İstanbul: Pinhan.

Haase, D. ( 2004). Fairy tales and feminism: New approaches. Detroit: Wayne State University.

Haase, D. (2016). Fairy tale. Folktales and fairy tales: Traditions and texts from around the world. (2nd edition), (D. Haase, A. E. Duggan, and H. J. Callow, Eds). S. Barbara. CA: Greenwood, 319322.

Harari Y. N. (2015). Hayvanlardan tanrllara sapiens, insan türünün kısa tarihi. (E. Genç, Çev.) İstanbul: Kolektif Kitap.

İncirkuş, F. A. ve Latif B. (2019). Öyküleyici metinler aracılığıyla eleştirel düşünme becerilerini değerlendirmeye yönelik bir rubrik. Ana Dili Ĕ̆itimi Dergisi. 7(3), 597-629.

Joosen, V. (2011). Sanat ve pedagoji arasında peri masalı uyarlamaları. (R. G. Saluk. Çev.) Millî Folklor, $92,152-160$.

Karadağ, M. (2004). Türk halk edebiyatı anlatı türleri. Ankara: Ürün.

Kökdemir, D. (2003). Belirsizlik durumlarında karar verme ve problem çözme. Doktora Tezi. Ankara Üniversitesi Sosyal Bilimler Enstitüsü. Ankara.

Kurnaz, A. (2019). Eleştirel düşünme ögretimi etkinlikleri planlama uygulama ve değerlendirme. Konya: Eğitim.

Laughey, D. (2010). Medya çalışmaları: Teoriler ve yaklaşımlar. (A. Toprak, Çev.) İstanbul: Kalkedon.

Masykuroh, Q. (2016). Physical and verbal violence in İndonesian folktales retold in children's books. Kajian Linguistik dan Sastra, 1(1), 26-34. 
Nas, R. (2004). Örneklerle çocuk edebiyatı. Ezgi.

Nisbett, R. E. (2006). Düşüncenin Coğrafyası-Doğulular ile batılılar nasıl ve neden birbirinden farklı düşünürler? (G. Ç. Güven, Çev.) İstanbul: Varlık.

Nosich, M. G. (2012). Eleştirel düşünme ve disiplinlerarası eleştirel düşünme rehberi. (B. Aybek. Çev.) Ankara: An1.

Oğuz, Öcal. (2010). Türkiye'de mit ve masal çalışmaları veya bir olumsuzlama ve tek-tipleştirme öyküsü. Millî Folklor, 22 (85), 36-45.

Ong, W. J. (2010). Sözlü ve yazılı kültür: Sözün teknolojileşmesi. (S. P. Bann, Çev.) İstanbul: Metis.

Röhrich, L. (2006). Halk anlatısı araştırmasında anlam arayışı. (K. M. Korkmaz, Çev.) Halkbiliminde kuramlar ve yaklaşımlar. Ankara: Millî Folklor, 128-145.

Özdemir, N. (2010). Mizah, eleştirel düşünce ve bilgelik: Nasreddin Hoca. Millî Folklor, 87, 27- 40.

Öztürk, O. (2012). Özerk benlik, kul benlik. İstanbul: Okuyan Us.

Özünel, E. Ö. (2011). Yazının izinde masal haritalarını okuma denemesi: Masal tarihine yeniden bakmak. Millî Folklor, 91, 60-71.

Ulu, A. E. (2018). Feminist yazının postmodern ifadesi: Masal parodileri. Journal of International Social Research, 11(60), 211-219.

Propp, V. (2001). Masalın biçimbilimi, olağanüstü masalların yapısı. (M. Rifat, S. Rifat, Çev.) İstanbul: $\mathrm{Om}$.

Pilancı, H. (2008). Çağdaş eğitimde halk edebiyatının kullanılması. Anadolu Üniversitesi. Ankara: 2008 .

Semerci, N. vd. (2019). Eleştirel düşünme engelleri (ELDEN) ölçeği: Geçerlik ve güvenirlik çalışmaları. Cumhuriyet Uluslararası Ĕgitim Dergisi, 8(1), 281-299.

Lévi Strauss, C. (2002). Yaban düşünce. (T. Yücel, Çev.) İstanbul: Yapı Kredi.

Seyidoğlu, B. (1975). Erzurum halk masalları üzerinde araştırmalar: Metinler ve açıklamalar. Erzurum: Atatürk Üniversitesi.

Sezer, M. Ö. (2012). Masal masal matitas. İstanbul: Evrensel.

Yavuz, M. H. (2002). Masallar ve eğitimsel işlevleri. Kültür Bakanlığı. Ankara.

Şahinel, S. (2015). Eleştirel düşünme. İçinde: Eğitimde Yeni Yönelimler. (Ö. Demirel, Ed.) Ankara: Pegem Akademi, 123-136.

Şimşek, E. (2017). Türk masallarının millî tipi: Keloğlan. Akra Kültür Sanat ve Edebiyat Dergisi, 5(11), 41-57.

Yıldırım, A. ve Hasan Ş. (2018). Sosyal bilimlerde nitel araştırma yöntemleri. Ankara: Seçkin Akademi ve Mesleki.

\section{Elekronik kaynaklar}

URL-1: Facione, A. P. (2013). Critical thinking: What it is and why it counts.( Erişim tarihi: 5 Nisan 2020) (https://www.academia.edu/5903883/Critical_thinking_what_it_is_and_why_it_counts) 
URL-2: Finlayson, M. A. (2012). Learning narrative structure from annotated folktales. Doktora tezi. Massachusetts Institute of Technology. (Erişim tarihi: 12 Nisan 2020). (http://hdl.handle. net/1721.1/71284)

URL-3: Vučković, D. (2018). A fairy tale (r) evolution: the value and the critical reading of fairy tales in the contemporary educational context. Pp. 309-336. (Erişim tarihi: 7 Şubat 2020 (https://www. researchgate.net/publication/329629330)

URL-4: Wee, S-J, Kyoung J. K. and Youngmi L. (2019). 'Cinderella did not speak up': critical literacy approach using folk/fairy tales and their parodies in an early childhood classroom. Early Child Development and Care. 189.11, pp.1874-1888. (Erişim tarihi: 25 Nisan 2020) (https://www. researchgate.net/publication/322005506)

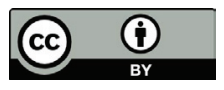

Bu eser Creative Commons Atıf 4.0 Uluslararası Lisansı ile lisanslanmıştır.

(This work is licensed under a Creative Commons Attribution 4.0 International License). 